NBER WORKING PAPER SERIES

\title{
ENERGY EFFICIENCY ECONOMICS AND POLICY
}

\author{
Kenneth Gillingham \\ Richard G. Newell \\ Karen Palmer \\ Working Paper 15031 \\ http://www.nber.org/papers/w15031 \\ NATIONAL BUREAU OF ECONOMIC RESEARCH \\ 1050 Massachusetts Avenue \\ Cambridge, MA 02138 \\ June 2009
}

This manuscript was prepared for the Annual Review of Resource Economics, Volume 1, forthcoming. The authors appreciate the very helpful research assistance of Maura Allaire, as well as useful comments from James Sweeney, Timothy Brennan, Maximilian Auffhammer, Richard Howarth, Danny Cullenward, and Sebastien Houde. This research was funded in part by the Resources for the Future Electricity and Environment Program, a special gift to RFF from Exelon for work on Energy Efficiency, and the U.S. Environmental Protection Agency STAR Fellowship program. The views expressed herein are those of the author(s) and do not necessarily reflect the views of the National Bureau of Economic Research.

NBER working papers are circulated for discussion and comment purposes. They have not been peerreviewed or been subject to the review by the NBER Board of Directors that accompanies official NBER publications.

(C) 2009 by Kenneth Gillingham, Richard G. Newell, and Karen Palmer. All rights reserved. Short sections of text, not to exceed two paragraphs, may be quoted without explicit permission provided that full credit, including $(\mathcal{C}$ notice, is given to the source. 
Energy Efficiency Economics and Policy

Kenneth Gillingham, Richard G. Newell, and Karen Palmer

NBER Working Paper No. 15031

June 2009

JEL No. H23,Q41,Q48

\begin{abstract}
$\underline{\text { ABSTRACT }}$
Energy efficiency and conservation are considered key means for reducing greenhouse gas emissions and achieving other energy policy goals, but associated market behavior and policy responses have engendered debates in the economic literature. We review economic concepts underlying consumer decision making in energy efficiency and conservation and examine related empirical literature. In particular, we provide an economic perspective on the range of market barriers, market failures, and behavioral failures that have been cited in the energy efficiency context. We assess the extent to which these conditions provide a motivation for policy intervention in energy-using product markets, including an examination of the evidence on policy effectiveness and cost. Although theory and empirical evidence suggests there is potential for welfare-enhancing energy efficiency policies, many open questions remain, particularly relating to the extent of some key market and behavioral failures.
\end{abstract}

Kenneth Gillingham

Stanford University

Stanford, California 94309

kgilling@stanford.edu

Richard G. Newell

Nicholas School of the Environment

Duke University

Box 90227

Durham, NC 27708

and NBER

richard.newell@duke.edu
Karen Palmer

Resources for the Future

1616 P Street, NW

Washington, DC 20036

palmer@rff.org 


\title{
Energy Efficiency Economics and Policy ${ }^{1}$
}

\author{
Kenneth Gillingham, Richard G. Newell, and Karen Palmer
}

\section{INTRODUCTION}

Energy efficiency and conservation have long been critical elements in the energy policy dialogue, and they have taken on a renewed importance as concerns about global climate change and energy security have intensified. Many advocates and policy makers hold that reducing the demand for energy is essential to meeting these challenges, and analyses tend to find that demand reductions can be a cost-effective means of addressing these concerns. With such great policy interest, a significant literature has developed over the past 30 years, providing an economic framework for addressing energy efficiency and conservation, as well as empirical estimates of how consumers respond to policies to reduce the demand for energy.

We begin by defining a few terms to put the literature in context. First, it is important to conceptualize energy as an input into the production of desired energy services (e.g., heating, lighting, motion), rather than as an end in itself. In this framework, energy efficiency is typically defined as the energy services provided per unit of energy input. For example, the energy efficiency of an air conditioner is the amount of heat removed from air per kilowatt-hour (kWh) of electricity input. At the individual product level, energy efficiency can be thought of as one of a bundle of product characteristics, alongside product cost and other attributes (Newell et al. 1999). At a more aggregate level, the energy efficiency of a sector or of the economy as a whole can be measured as the level of gross domestic product per unit of energy consumed in its

\footnotetext{
${ }^{1}$ This manuscript was prepared for the Annual Review of Resource Economics, Volume 1, forthcoming.
} 
production (for analyses of the determinants of energy intensity at the state and national levels, see, for example, Metcalf 2008, Sue Wing 2008).

In contrast, energy conservation is typically defined as a reduction in the total amount of energy consumed. Thus, energy conservation may or may not be associated with an increase in energy efficiency, depending on how energy services change. That is, energy consumption may be reduced with or without an increase in energy efficiency, and energy consumption may increase alongside an increase in energy efficiency. These distinctions are important when considering issues such as the "rebound effect," whereby the demand for energy services may increase in response to energy efficiency-induced declines in the marginal cost of energy services. The distinction is also important in understanding the short- versus long-run price elasticity of energy demand, whereby short-run changes may depend principally on changes in consumption of energy services, whereas longer-run changes include greater alterations of the energy efficiency of the equipment stock.

One must also distinguish between energy efficiency and economic efficiency. Maximizing economic efficiency—typically operationalized as maximizing net benefits to society —is generally not going to imply maximizing energy efficiency, which is a physical concept and comes at a cost. An important issue arises, however, regarding whether private economic decisions about the level of energy efficiency chosen for products are economically efficient. This will depend on the economic efficiency of the market conditions the consumer faces (e.g., energy prices, information availability) as well as the economic behavior of the individual decision maker (e.g., cost-minimizing behavior).

Market conditions may depart from efficiency if there are market failures, such as environmental externalities or imperfect information. Aside from such market failures, most 
economic analysis of energy efficiency has taken cost-minimizing (or utility/profit-maximizing) behavior by households and firms as a point of departure in analysis. Some literature, however, has focused more closely on the decision-making behavior of economic actors, identifying potential "behavioral failures" that lead to deviations from cost minimization and motivated at least partly by results from the field of behavioral economics. Much of the economic literature on energy efficiency therefore seeks to conceptualize energy efficiency decision making, to identify the degree to which market or behavioral failures may present an opportunity for net-beneficial policy interventions, and to evaluate the realized effectiveness and cost of actual policies.

This line of research has important implications both for assessing the cost of correcting market failures—such as environmental externalities—and for clarifying the role of policies that are oriented toward the correction of behavioral failures. For example, if behavioral failures lead to underinvestment in energy efficiency, then some reductions in energy-related emissions could be available at low or even negative cost. At the same time, policies that provide an efficient means of correcting environmental externalities—such as an emissions price-may not be well suited to inducing these relatively low-cost energy and emission reductions. In principle, a set of policies addressing both market and behavioral failures could, therefore, potentially provide a more efficient overall response. In practice, the value of individual policy components depends on the extent of existing market problems and the ability of specific policies to correct these problems in a net beneficial manner.

This article views the literature through this perspective and begins by introducing the notion of energy efficiency as an investment in producing energy services. After presenting evidence of energy market influences on energy efficiency, we then turn to identifying and examining empirical evidence on a range of market and behavioral failures that have been 
discussed in the energy efficiency literature. We then address the implications of this evidence for policy interventions and briefly review the empirical evidence on the effectiveness and cost of policy, including price policies and information policies. Finally, we provide overall conclusions. We limit the scope of this study primarily to energy efficiency and conservation in buildings and appliances and do not address transportation in detail. Nonetheless, most of the same conceptual and empirical issues carry over to transportation as well.

\section{ENERGY EFFICIENCY AS AN INVESTMENT IN PRODUCING ENERGY SERVICES}

From an economic perspective, energy efficiency choices fundamentally involve investment decisions that trade off higher initial capital costs and uncertain lower future energy operating costs. In the simplest case, the initial cost is the difference between the purchase and installation cost of a relatively energy-efficient product and the cost of an otherwise equivalent product that provides the same energy services but uses more energy. The decision of whether to make the energy-efficient investment requires weighing this initial capital cost against the expected future savings. Assessing the future savings requires forming expectations of future energy prices, changes in other operating costs related to the energy use (e.g., pollution charges), intensity of use of the product, and equipment lifetime. Comparing these expected future cash flows against the initial cost requires discounting the future cash flows to present values. Holding consumption of energy services constant, a privately optimal decision would entail choosing the level of energy efficiency to minimize the present value of private costs, whereas economic efficiency at a societal level would entail minimizing social costs. This makes energy efficiency different in character from many other product attributes for which there may not be a well-defined notion of what constitutes optimal or "rational" behavior on the part of the individual. 
This conceptualization of the problem maps directly into a production function framework, where capital and energy are viewed as inputs into the production of energy services. Along an isoquant describing a given level of energy services, the cost-minimizing level of energy use (and thus energy efficiency) is found at the point of tangency where the marginal increase in capital cost with respect to energy reduction is equal to their relative price (in presentvalue terms) (Figure 1). As described above, the relative price will depend on the capital cost of efficiency improvements, the discount rate, expected energy prices, equipment utilization, and decision-time horizon. This framework applies at the household level as well as at a broad sectoral or multisectoral level where energy and capital are used to produce energy services. ${ }^{2}$

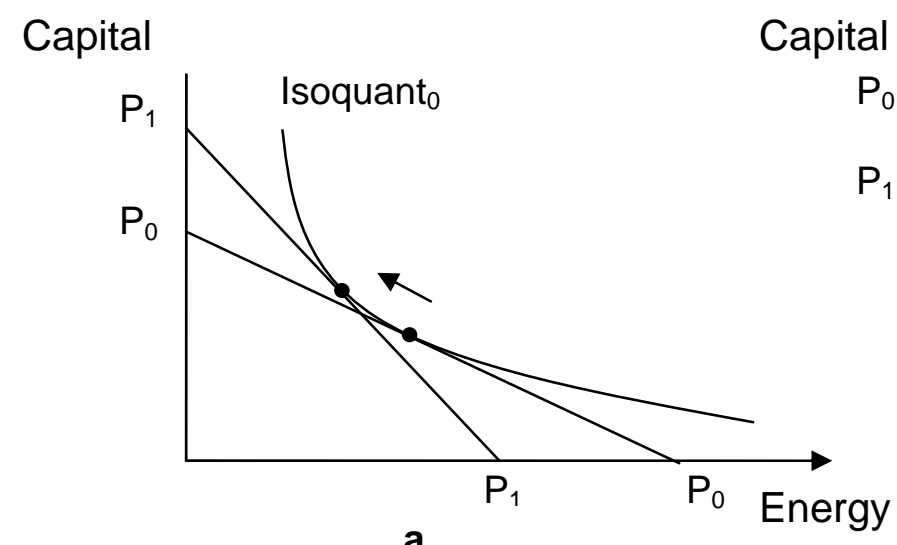

a

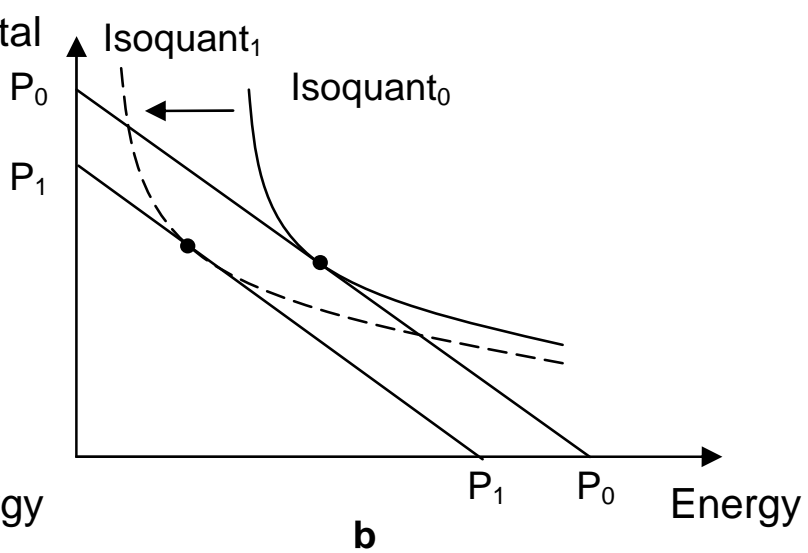

b

\section{Figure 1 (a) Energy efficiency-improving substitution versus (b) energy-saving technological change.}

Focusing on the household level as an example, greater energy efficiency can be driven by market forces in two ways within this production function framework. First, households may move along the energy-services isoquant by substituting capital for energy in response to a

\footnotetext{
${ }^{2}$ Understanding the economic forces governing the rate and direction of energy-related technological change at the product, sectoral, and aggregate levels has been an important area of research, particularly in the context of climate change modeling. For a review of literature devoted to this topic, which is beyond the scope of this paper, see Gillingham et al. (2008).
} 
change in relative prices (Figure $1 a$, with relative prices changing from $P_{0}$ to $P_{1}$ ). Second, technological change that shifts the isoquant in a way favoring (i.e., biased toward) greater energy efficiency (Figure $1 b$, with isoquant ${ }_{0}$ shifting to isoquant ${ }_{1}$ ) could change the production possibilities available to households. In contrast, energy conservation not driven by energy efficiency improvements would be associated with a lower level of energy services (i.e., a lesser isoquant).

Market failures can be represented within this framework as a divergence of the relative prices used for private decisions from the economically efficient prices. For example, both unpriced environmental externalities and missing information on the energy intensity of product use would tend to lower the relative price of energy, leading to choices of inefficiently low energy efficiency (e.g., $P_{0}$ compared with $P_{1}$ in Figure $1 a$ ). Note that this framework presupposes optimizing behavior by the consumer, given available information—an assumption subject to debate within the behavioral economics literature, as discussed below.

The next section further explores the role of energy markets in governing energy efficiency decisions. Section 4 then identifies potential market and behavioral failures that may lead to suboptimal decisions.

\section{ENERGY MARKET INFLUENCES ON ENERGY EFFICIENCY}

Energy markets and market prices influence consumer decisions regarding how much energy to consume and whether to invest in more energy-efficient products and equipment. An increase in energy prices will result in some energy conservation in the short run; however, short-run changes in energy efficiency tend to be limited owing to the long lifetimes and slow turnover of energy-using appliances and capital equipment. Nonetheless, if an energy price increase is 
persistent, it also is more likely to significantly affect energy efficiency adoption, as consumers replace older capital equipment and firms have time to develop new products and processes.

The extent of demand responsiveness to changes in price is captured in the price elasticity of energy demand. Table 1 presents the ranges of energy own-price elasticity estimates in the literature. Long-run price elasticities are larger than short-run elasticities, corresponding to more

Table 1 Ranges of estimates of energy own-price elasticities ${ }^{a}$

\begin{tabular}{|c|c|c|c|c|}
\hline & \multicolumn{2}{|r|}{ Short run } & \multicolumn{2}{|r|}{ Long run } \\
\hline & Range & References & Range & References \\
\hline \multicolumn{5}{|l|}{ Residential } \\
\hline Electricity & $0.14-0.44$ & Dahl (1993) & $0.32-1.89$ & $\begin{array}{l}\text { Bernstein \& Griffin (2005), } \\
\text { Hsing (1994) }\end{array}$ \\
\hline Natural gas & $0.03-0.76$ & $\begin{array}{l}\text { Bohi \& Zimmerman } \\
\text { (1984), Dahl (1993) }\end{array}$ & $0.26-1.47^{\mathrm{b}}$ & $\begin{array}{l}\text { Bohi \& Zimmerman (1984), } \\
\text { Dahl(1993) }\end{array}$ \\
\hline Fuel oil & $0.15-0.34$ & Wade (2003) & $0.53-0.75$ & Dahl (1993), Wade (2003) \\
\hline \multicolumn{5}{|l|}{ Commercial } \\
\hline Electricity & $0-0.46$ & Dahl (1993), & $0.24-1.36$ & Wade (2003), Dahl (1993) \\
\hline Natural gas & $0.14-0.29$ & $\begin{array}{l}\text { Dahl (1993), Wade } \\
\text { (2003) }\end{array}$ & $0.40-1.38$ & $\begin{array}{l}\text { Wade (2003), Bohi \& } \\
\text { Zimmerman (1984), }\end{array}$ \\
\hline Fuel oil & $0.13-0.49$ & $\begin{array}{l}\text { Dahl (1993), Wade } \\
(2003)\end{array}$ & $0.39-3.5$ & $\begin{array}{l}\text { Wade (2003), Newell \& Pizer } \\
\text { (2008) }\end{array}$ \\
\hline \multicolumn{5}{|l|}{ Industrial } \\
\hline Electricity & $0.11-0.28$ & $\begin{array}{l}\text { Bohi \& Zimmerman } \\
\text { (1984), Dahl (1993) }\end{array}$ & $0.22-3.26$ & $\begin{array}{l}\text { Bohi \& Zimmerman (1984), } \\
\text { Dahl (1993) }\end{array}$ \\
\hline Natural gas ${ }^{b}$ & $0.51-0.62$ & $\begin{array}{l}\text { Bohi \& Zimmerman } \\
\text { (1984) }\end{array}$ & $0.89-2.92$ & $\begin{array}{l}\text { Dahl (1993), Bohi \& } \\
\text { Zimmerman (1984) }\end{array}$ \\
\hline Fuel oil & 0.11 & Dahl (1993) & $0.5-1.57^{\mathrm{c}}$ & Bohi \& Zimmerman (1984) \\
\hline
\end{tabular}

${ }^{\mathrm{a}}$ Absolute values shown; all values are negative.

${ }^{\mathrm{b}}$ Estimates drawn largely from regional studies.

${ }^{\mathrm{b}}$ Estimates for 19 states.

energy efficiency improvements as capital turns over. On average, natural gas price elasticities are greater than electricity or fuel oil elasticities. Note that, because they are based on actual consumer behavior, these price elasticity estimates include any increase in consumption of energy services that might occur in response to a lower unit cost of energy services resulting from increased energy efficiency (i.e., the rebound effect). 
Other studies have focused specifically on factors influencing technology adoption, finding that higher energy prices are associated with significantly greater adoption of energyefficient equipment (Anderson \& Newell 2004, Hassett \& Metcalf 1995, Jaffe et al. 1995). Further upstream in the technology development process, Newell et al. (1999) and Popp (2002) found energy-efficient innovation is also significantly determined by energy prices (for a review, see Popp et al. 2009). Empirical estimates, therefore, demonstrate a substantial degree of responsiveness of energy utilization as well as energy-efficient technology adoption and innovation to changes in energy price.

\section{POTENTIAL MARKET AND BEHAVIORAL FAILURES}

Much of the literature on energy efficiency focuses on elucidating the potential rationales for policy intervention and evaluating the effectiveness and cost of such interventions in practice. Within this literature, there is a long-standing debate surrounding the commonly cited "energy efficiency gap.” There are several ways to view this gap. At its core, the gap refers to a significant difference between observed levels of energy efficiency and some notion of optimal energy use (Jaffe et al. 2004). That notion of optimal energy use has at times focused on maximizing physical energy efficiency, which will not generally coincide with maximal economic efficiency because energy efficiency comes at a cost. Within the investment framework described above, the energy efficiency gap takes the form of underinvestment in energy efficiency relative to a description of the socially optimal level of energy efficiency. Such underinvestment is also sometimes described as an observed rate or probability of adoption of energy-efficient technologies that is "too slow."

Often, the efficiency gap is illustrated by a comparison of the market discount rate and relatively high "implicit discount rates" that are implied by consumer choices over appliances 
with different costs and energy efficiencies (Hausman 1979). The empirical evidence is relatively well established; in a number of studies published primarily in the late 1970s and early 1980s, analysts using a variety of methodologies found implicit discount rates ranging from $25 \%$ to over $100 \%$ (Sanstad et al. 2006, Train 1985).

Economists have posited a number of explanations to account for part or all of the apparent gap: hidden costs not accounted for by the analyst, including search costs as well as reductions in other product attributes (e.g., lighting quality) (Jaffe et al. 2004); lower energy savings than assumed by the analyst, owing in part to heterogeneity of consumers (Hausman \& Joskow 1982); uncertain future energy savings implying rational consumers should put more weight on the initial cost (Sutherland 1991); the irreversibility of energy efficiency investments and the associated option value of waiting to invest (Hassett \& Metcalf 1993, 1995; van Soest \& Bulte 2000); and the possibility that consumers are appropriately forming expectations about future energy prices but energy analysts are using incorrect proxies for these expectations (Jaffe et al. 2004). For example, studies have found that actual savings from past utility-sponsored programs achieved 50\%-80\% of predicted savings (Hirst 1986, Sebold \& Fox 1985), although a more recent study by Auffhammer et al. (2008) suggests that utilities have improved their abilities to predict savings. Similarly, Metcalf \& Hassett (1999) found that, once all costs are accounted for, the realized return to attic insulation is much below the returns promised by engineers and manufacturers, and at $9.7 \%$, it is consistent with the interest rate suggested by standard investment theory. Others have argued that the energy efficiency gap must not exist because rational optimizing consumers would not be willing to ignore large benefits- the proverbial \$20 bill on the sidewalk (Sutherland 1996). 
Conversely, other papers that examined these explanations for why there may not be a gap found some of them lacking. Metcalf (1994) found that the uncertainty of future energy savings described in Sutherland (1991) should actually lead a rational investor to require a rate of return that is lower than the market discount rate, because energy efficiency investments will tend to serve as a hedge against other risks. Sanstad et al. (1995) showed that the option value analysis of Hassett \& Metcalf $(1993,1995)$ suggests an implicit discount rate much lower than observed implicit discount rates, even when taking irreversibility into account. Howarth \& Sanstad (1995) discussed heterogeneity and hidden costs as possible concerns, but they suggested that analysts are cognizant of these issues and are careful to take them into account. For example, Koomey \& Sanstad (1994) paid close attention to confounding factors such as heterogeneity and hidden costs and still found high implicit discount rates for efficient ballasts for commercial lighting and consumer purchases of refrigerators.

Other papers focus on distinguishing market barriers to the adoption of energy-efficient technologies from market failures. Market barriers can be defined as any disincentives to the adoption or use of a good (Jaffe et al. 2004). Market barriers may or may not be market failures in the traditional welfare economic sense. Potential market barriers described in the broader energy efficiency literature occasionally include such factors as low energy prices, fluctuating energy prices, or high technology costs, which are clearly not market failures on their own. Systematic biases in consumer decision making that lead to underinvestment in energy efficiency relative to the cost-minimizing level are also often included among market barriers. Following the review by Shogren \& Taylor (2008) of behavioral economics, however, we classify these biases as "behavioral failures." In the present context, we consider behavioral failures to represent consumer behavior that is inconsistent with utility maximization or, in the current 
context, with energy-service cost minimization. In contrast, market failure analysis is distinct in presupposing individual rationality and instead focusing on the conditions surrounding interactions among economic agents and society.

There is an economic rationale for policies to correct market barriers if they represent market or behavioral failures (Shogren \& Taylor 2008). Table 2 provides a summary of potential market and behavioral failures relating to energy efficiency and conservation, along with policy responses that have been implemented, or could be implemented, to address these problems in cases where they are found to be significant. We focus on the most commonly raised market and behavioral failures but do not prejudge whether they are empirically significant problems for energy efficiency and conservation. ${ }^{3}$ The remainder of this section discusses each of these potential concerns in turn. Then in Section 5, we review experience with policies that have been proposed and implemented, in part, as a response to these concerns.

\subsection{Energy Market Failures}

The common theme in energy market failures is that energy prices do not reflect the true marginal social cost of energy consumption, either through environmental externalities, averagecost pricing, or national security. Environmental externalities associated with the production and consumption of many sources of energy lead to emissions of greenhouse gases and other air pollutants resulting in costs that are borne by others - that is, they are not internalized by the individual energy consumer. Absent policy, an environmental externality leads to an overuse of energy relative to the social optimum and, hence, underinvestment in energy efficiency and

\footnotetext{
${ }^{3}$ In addition to the issues discussed below, Fischer (2005) developed the economic theory supporting a role of price discrimination in imperfectly competitive markets in diminishing producers' incentives to improve energy efficiency of low-end products. Ruderman et al. (1987)discussed the effects of inseparability of product features on markets for energy efficiency, although associated inefficiencies should be minimal in competitive markets.
} 


\section{Table 2 Commonly cited market and behavioral failures relevant to energy efficiency}

along with potential policy responses

\begin{tabular}{|c|c|}
\hline Potential market failures & Potential policy options \\
\hline Energy market failures & \\
\hline Environmental externalities & Emissions pricing (tax, cap and trade) \\
\hline Average-cost electricity pricing & Real-time pricing, market pricing \\
\hline Energy security & Energy taxation, strategic reserves \\
\hline Capital market failures & \\
\hline Liquidity constraints & Financing/loan programs \\
\hline Innovation market failures & \\
\hline R\&D spillovers ${ }^{\mathrm{a}}$ & R\&D tax credits, public funding \\
\hline Learning-by-doing spillovers & Incentives for early market adoption \\
\hline Information problems & \\
\hline Lack of information, asymmetric information & Information programs \\
\hline Principal-agent problems & Information programs \\
\hline Learning by using & Information programs \\
\hline Potential behavioral failures & Potential policy options \\
\hline Prospect theory & Education, information, product standards \\
\hline Bounded rationality & Education, information, product standards \\
\hline Heuristic decision making & Education, information, product standards \\
\hline
\end{tabular}

${ }^{\mathrm{a}} \mathrm{R} \& \mathrm{D}$, research and development.

conservation. Although there is no debate over the existence of environmental externalities, the magnitude of such externalities and their degree of internalization is uncertain and hard to measure. Gillingham et al. (2006) reviewed the literature on environmental externalities from the production of electricity and found that past policies to reduce electricity use provided monetized benefits from the reduction in $\mathrm{CO}_{2}$, nitrous oxides $\left(\mathrm{NO}_{\mathrm{x}}\right)$, sulfur dioxide $\left(\mathrm{SO}_{2}\right)$, and fine particulate matter $\left(\mathrm{PM}_{10}\right)$ that were on the order of $10 \%$ of the direct value of the electricity savings. Environmental externalities, largely in the form of air emissions, also exist with other fossil fuels, such as home-heating oil or propane. To the extent that energy prices do not currently internalize these externalities (which varies by pollution type), the market will provide a level of energy efficiency that is too low from a societal point of view. The economically 
optimal policy response is to price emissions, which will indirectly stimulate greater energy efficiency.

Prices faced by consumers in electricity markets also may not reflect marginal social costs due to the common use of average-cost pricing under utility regulation. Average-cost pricing could lead to under- or overuse of electricity relative to the economic optimum. On one hand, to the extent that average costs are above marginal costs as a result of amortized fixed costs, consumers face a price above the economically optimal price, thus encouraging underuse of electricity. On the other hand, average-cost prices depend on the average cost of the mix of generators used to produce electricity. Market-based pricing produces daily or hourly wholesale prices that reflect the cost of the marginal generator and retail prices that typically reflect the average of these marginal costs over a period of months. Time-of-use (TOU) prices vary in a preset manner by time of day or season, whereas real-time pricing (RTP) directly conveys information about the current marginal cost of generation and transmission in the price, updated at an hourly or even more frequent basis. If consumers face prices that are at times too low (peak times) and at other times too high (off-peak), they will overuse electricity during the peak times and underuse it during the off-peak relative to the social optimum (Joskow \& Tirole 2007).

RTP and, to a lesser degree, TOU pricing can partly alleviate this market failure (which could alternatively be described as a policy failure). Of course, the cost of implementing TOU pricing or RTP may exceed the benefits, and there may be other market failures related to the adoption of real-time meters (Brennan 2004). However, recent evidence from the Anaheim Critical Peak Pricing Experiment suggests that, with recent technology advances, a variation of RTP implemented during peak periods has significant potential to improve social welfare, with little effect on use in off-peak periods (Wolak 2006). Whether there would be conservation of 
total energy use with a comprehensive RTP scheme during all time periods is less clear. Similarly, the effect of TOU pricing or RTP on energy efficiency investments is unclear and would depend on the pricing that exists during the time those investments would be used.

Some authors have suggested that there are national security external costs from the United States’ dependence on certain energy sources-particularly oil from unstable regions of the world - that consumers do not face in energy prices or therefore take into account in their energy-use decisions (Bohi \& Toman 1996, Bohi \& Zimmerman 1984). Although these concerns are associated primarily with transportation-related consumption of oil, they are relevant to building energy consumption through fuel oil consumption for heating and the association between natural gas and oil markets. Economic and other analyses of the national security risks of energy consumption is not entirely satisfying, in part because of the lumpiness of the problem. On the margin, reducing oil consumption would not likely change the associated security risks, nor the military and diplomatic expenditures undertaken in response. Nonetheless, a long-term larger reduction may reduce these risks, and to the extent that these risks are not fully reflected in the price of relevant energy resources, there will be a resulting underinvestment in energy efficiency.

\subsection{Information Problems}

Information problems are consistently raised in the energy efficiency literature and, along with behavioral failures, are often given as the primary explanation for the energy efficiency gap (Sanstad et al. 2006). Specific information problems cited include consumers’ lack of information about the availability of and savings from energy-efficient products, asymmetric information, principal-agent or split-incentive problems, and externalities associated with learning by using. The following descriptions take the consumers’ perspective, but several of 
these same information problems have been studied in the context of decision making by firms (DeCanio 1993, 1994a,b; DeCanio \& Watkins 1998; Stein 2003). As discussed in Section 5, if such problems are significant and correctable, they may warrant labeling and other information programs.

Lack of information and asymmetric information are often given as reasons why consumers systematically underinvest in energy efficiency. The idea is that consumers often lack sufficient information about the difference in future operating costs between more-efficient and less-efficient goods necessary to make proper investment decisions (Howarth \& Sanstad 1995). This argument can be consistent with cost-minimizing behavior, if we assume that under perfect information consumers would reach a privately optimal outcome. Alternatively, information problems may occur when there are behavioral failures, so that consumers are not appropriately taking into account future reductions in energy costs when making present investments in energy efficiency. We discuss information problems in the context of behavioral failures in Section 5.

Asymmetric information, where one party involved in a transaction has more information than another, may lead to adverse selection (Akerlof 1970). In the context of energy efficiency, adverse selection could imply that sellers of energy-efficient technologies that would provide clear ex post benefits to consumers are unable to perfectly transfer this information to buyers if the energy efficiency is unobserved (Howarth \& Sanstad 1995). The sellers of every product would have an incentive to suggest that the energy efficiency of the product is high, but because the buyers cannot observe the energy efficiency, they may ignore it in their decision. The model by Howarth \& Andersson (1993), which incorporates explicit transaction costs of transferring information, formally describes how this circumstance could lead to an underinvestment in 
energy efficiency. Whereas transaction costs in this context may be a source of market failure, transaction costs in general may be legitimate and not a reason for intervening in markets.

The principal-agent or split-incentive problem describes a situation where one party (the agent), such as a builder or landlord, decides the level of energy efficiency in a building, while a second party (the principal), such as the purchaser or tenant, pays the energy bills. When the principal has incomplete information about the energy efficiency of the building, the first party may not be able to recoup the costs of energy efficiency investments in the purchase price or rent charged for the building. The agent will then underinvest in energy efficiency relative to the social optimum, resulting in a market failure (Jaffe \& Stavins 1994). Murtishaw \& Sathaye (2006) attempted to quantify the magnitude of the principal-agent problem for four end uses: space heating, refrigerators, water heating, and lighting. They found that the principal-agent problem is potentially relevant to $25 \%$ of refrigerator energy use, $66 \%$ of water heating energy use, $48 \%$ of space heating energy use, and $2 \%$ of lighting energy use, although they did not quantify the degree to which energy efficiency decisions in these cases have actually been inefficient. Levinson \& Niemann (2004) found that tenants whose electric bills are included in their rental contracts consume significantly greater energy than tenants who pay their own electric bills.

Positive externalities associated with learning by using can exist where the adopter of a new energy-efficient product creates knowledge about the product through its use, and others freely benefit from the information generated about the existence, characteristics, and performance of the product. This phenomenon is not unique to energy efficiency (Jaffe et al. 2004). In the context of demand-side management programs, some studies have distinguished learning-by-using spillovers into “free drivers” and program spillovers (Blumstein \& Harris 
1993, Eto et al. 1996). Free drivers are nonparticipants who install energy-efficient products as a result of hearing about them from program participants. Program spillovers occur when the participating household installs additional energy-efficient products, without rebates, as a result of the information they learned through participation in the program.

\subsection{Liquidity Constraints in Capital Markets}

Blumstein et al. (1980) first described liquidity constraints that hinder access to financing for energy-efficient investments as a market barrier. Some purchasers of equipment may choose the less energy-efficient product owing to lack of access to credit, resulting in underinvestment in energy efficiency and reflected in an implicit discount rate that is above typical market levels. This effect is a variation of a market failure associated with a lack of access to capital that is widely discussed in the development economics literature, and it applies to any capital-intensive investment, not just energy-efficient products (Ray 1998). The extent to which liquidity constraints are an issue in energy efficiency has yet to be established empirically. Some evidence indicates that only a small percentage of home improvements are funded by loans, which could imply liquidity constraints are important for only a small fraction of energy efficiency investments or that liquidity constraints effectively force most energy efficiency investments to be self-financed (Berry 1984).

In industry and government, a common financing constraint is the institutional disconnect between capital and operating budgets, but energy-services performance contracts have developed to fill this niche. In some cases, such as for industrial customers, energy-service providers pay the capital cost and receive a share of the resulting savings. In other cases, such as for government and institutional customers, the customer can borrow at a lower interest rate than the energy-service provider, so it makes greater financial sense for the customer to make the 
investment. In such cases, the energy-service providers recommend energy efficiency

improvements, guarantee the operating cost savings, and pay the difference if those savings are not realized—often allowing for the repayment of the capital cost to be treated as an operating expense (Zobler \& Hatcher 2003). In addition, if liquidity constraints are an issue for energy efficiency investments, then they will also constrain other types of investments, and any potential solution would have to reach well beyond energy efficiency policy.

Golove \& Eto (1996) described a case of asymmetric information where consumers are unable to transfer information to their lenders about the relative certainty of operating cost savings from an efficiency investment. Thus, the lender cannot determine the likelihood of repayment and is less likely to approve of the loan. Golove \& Eto claimed the resulting credit constraints imply that consumers should be given a lower interest rate than lenders are willing to offer, and thus consumers faced with the higher interest rate may underinvest in energy efficiency. The extent of this potential problem has not been measured empirically to our knowledge, and this problem of information transfer may apply to other costs as well, possibly altering the result. Energy-efficient mortgages from some lenders address this problem by crediting a home's energy efficiency when determining the interest rate or the size of the mortgage. Warranties may also address this problem privately.

\subsection{Innovation Market Failures}

R\&D spillovers may lead to underinvestment in energy-efficient technology innovation owing to the public good nature of knowledge, whereby individual firms are unable to capture the full benefits from their innovation efforts, which instead accrue partly to other firms and consumers. This is not particular to energy efficiency innovation; rather, it is a general feature of technological innovation, which manifests empirically as a social rate of return to $R \& D$ that is 
approximately two to four times higher than the private rate of return (Griliches 1995, Hall 1996, Nadiri 1993). If energy is underpriced relative to the social optimum, this innovation problem will be magnified in the context of energy-saving technologies (Goulder \& Schneider 1999, Jaffe et al. 2005, Schneider \& Goulder 1997).

Learning by doing (LBD) refers to the empirical observation that, as cumulative production of new technologies increases, the cost of production tends to decline as the firm learns from experience how to reduce its costs (Arrow 1962). LBD may be associated with a market failure if the learning creates knowledge that spills over to other firms in the industry, lowering the costs for others without compensation to the original investing firm (Fischer \& Newell 2008, van Benthem et al. 2008). In the energy context, LBD processes have been empirically investigated and applied primarily to fledgling low-carbon electricity-generating technologies in the context of energy and climate policy modeling. The empirical evidence on learning in terms of energy-using equipment is very limited, and what does exist focuses generally on product cost reductions rather than learning specifically with respect to improving energy efficiency (see, e.g., Bass 1980). It is also difficult to empirically distinguish learning from other factors that affect product costs and prices. Further research is needed to examine learning in energy-efficient technologies and ascertain the degree to which the learning spills over to other firms. The potential for positive externalities from LBD is not unique to energy: It may occur with any new technology that displays nonappropriable learning characteristics.

\subsection{Behavioral Failures}

The behavioral economics literature has drawn attention to several systematic biases in consumer decision making that may be relevant to decisions regarding investment in energy efficiency. Similar insights can be gained from the literature on energy decision making in psychology and 
sociology (e.g., see Stern 1985; Lutzenhiser 1992, 1993). Frameworks incorporating such departures from perfect rationality have intuitive psychological appeal as well as an empirical basis from behavioral economic and psychological studies. The crucial question is whether these deviations from perfect rationality lead to significant systematic biases in energy efficiency decision making, and if so, whether these biases lead to under- or overinvestment in energy efficiency. Due to the limited economics literature in this area, in many cases we reference literature from other social sciences that bears directly on energy consumption-related behavior.

The behavioral economics literature draws upon cognitive psychology and other disciplines to inform experimental and theoretical analyses aimed at understanding how consumers make decisions. Behavioral economists tend to relax the classical microeconomic assumption of rational choice and replace it with bounded rationality or other heuristic decisionmaking methods (McFadden 1999). Behavioral economics has been motivated by evidence that consumers are not perfectly rational—even if they are given perfect information—and has developed a positive theory designed to understand how consumers make decisions in practice. In the energy efficiency context, the most relevant and common rationality assumption is that of behavior that minimizes present-value costs for a given level of energy-service provision.

The evidence that consumer decisions are not always perfectly rational is quite strong, beginning with the research by Tversky \& Kahneman indicating that both sophisticated and naïve respondents will consistently violate axioms of rational choice in certain situations (e.g., see Tversky \& Kahneman 1974, Kahneman \& Tversky 1979). Since then, an entire literature has developed examining when and how people violate the axioms of rational choice. Surveys of this literature of behavioral decision theory include Camerer (1997), McFadden (1999), Machina (1989), Rabin (1997), and Thaler (1991). Shogren \& Taylor (2008) and List \& Price (2009) 
provide reviews specifically in the context of resource and environmental economics. Our review follows the primary theme of behavioral economics by focusing on consumer decisions. Firms may also face some of the same issues, although competitive forces serve to moderate the significance of behavioral failures for firms (Shogren \& Taylor 2008).

The three primary themes that emerge from behavioral economics and have been applied in the context of energy efficiency are prospect theory, bounded rationality, and heuristic decision making. The prospect theory of decision making under uncertainty posits that the welfare change from gains and losses is evaluated with respect to a reference point, usually the status quo. In addition, consumers are risk averse with respect to gains and risk seeking with respect to losses, so that the welfare change is much greater from a loss than from an expected gain of the same magnitude (Kahneman \& Tversky 1979). This can lead to loss aversion, anchoring, status quo bias, and other anomalous behavior (Shogren \& Taylor 2008).

Bounded rationality suggests that consumers are rational but face cognitive constraints in processing information that lead to deviations from rationality in certain circumstances (Simon 1959, 1986). Heuristic decision making is related closely to bounded rationality and encompasses a variety of decision-making strategies that differ in some critical way from conventional utility maximization in order to reduce the cognitive burden of decision making. For example, Tversky (1972) developed the theory of elimination by aspects, wherein consumers use a sequential decision-making process where they first narrow their full choice set to a smaller set by eliminating products that do not have some desired feature or aspect (e.g., cost above a certain level), and then they optimize among the smaller choice set, possibly after eliminating further products. 
Not much economic literature empirically tests these behavioral hypotheses to uncover whether there is a systematic bias, either negative or positive, in decision making related to energy consumption. Hartman et al. (1991) empirically examined whether the status quo effect posited in prospect theory holds in the consumer valuation of reliable electric service. Though reliable electric service is only somewhat related to energy efficiency, they found that the status quo effect is significant in this case, suggesting that consumers are irrationally reluctant to move from the status quo and accept more likely interruptions in electricity service.

Empirically testing bounded rationality is even more difficult, for there is no single consensus model of bounded rationality in energy decision making (Sanstad \& Howarth 1994). Friedman \& Hausker (1988) developed a theoretical model using a particular structure of bounded rationality in which consumers do not have the ability to optimize their energy consumption in response to a tiered-rate structure of electricity prices. The model indicates that consumers will overconsume energy if the rate structure is increasing and underconsume if it is decreasing. Friedman (2002) tested this theoretical model using electric-utility data and exploited the increasing block structure of electricity rates to find that the empirical specification consistent with bounded rationality (and leading consumers to overconsume electricity) has more predictive power than one based on utility maximization.

Heuristic decision making in energy is similarly difficult to test empirically, although several papers in psychology have done so. Kempton \& Montgomery (1982) used a survey technique to find that consumers use simple heuristic techniques to determine their energy consumption, and these techniques systematically lead to underinvestment in energy efficiency. For example, Kempton \& Montgomery found that, for decisions regarding energy-efficient investments, consumers tended to use a simple payback measure where the total investment cost 
is divided by the future savings calculated using the energy price today, rather than the price at the time of the savings — effectively ignoring future changes in real fuel prices. Kempton et al. (1992) used similar methods, finding that consumers systematically miscalculate payback for air conditioner investments, again leading to overconsumption of energy.

Yates \& Aronson (1983) found that consumers attach disproportionate weight to the most psychologically vivid and observable factors, often called the salience effect. The salience effect may influence energy efficiency decisions, potentially contributing to an overemphasis on the initial cost of an energy-efficient purchase, leading to an underinvestment in energy efficiency (Wilson \& Dowlatabadi 2007). This may be related to evidence suggesting that decision makers are more sensitive to up-front investment costs than energy operating costs, although this evidence may also be the result of inappropriate measures of expectations of future energy use and prices (Anderson \& Newell 2004, Hassett \& Metcalf 1995, Jaffe et al. 1995).

Loewenstein \& Prelec (1992) developed a theoretical model of intertemporal choice that replaces the utility function with a value function that is more elastic for outcomes with large absolute magnitudes than for outcomes with small magnitudes, consistent with evidence in Thaler (1981) and Holcomb \& Nelson (1992). Thus, in this value function framework, discounting depends on the magnitude of the outcome. Applying this to the case of energy efficiency investments, flows of electricity savings are typically smaller than the annual returns from other types of investments and thus would be subject to higher rates of discount. Loewenstein \& Prelec posited that their model may capture a behavioral bias that implies a systematic underinvestment in energy efficiency relative to the consumers' cost-minimizing choice. To our knowledge, the model has not been empirically tested in the context of energy efficiency. 
This review reveals that the empirical literature testing behavioral failures specifically in the context of energy decision making is very limited. The literature in psychology and sociology discusses these biases further and provides some additional evidence of such biases (e.g., for a review of the approaches in the different fields as applied to energy, see Wilson \& Dowlatabadi 2007). The available evidence suggests that systematic biases may exist in consumer decision making that could lead to overconsumption of energy and underinvestment in energy efficiency. However, more fully understanding the magnitude of these biases, disentangling them from informational and other market failures, and measuring the ability of practicable policies to address these behavioral failures remain important areas for future research.

\section{ENERGY EFFICIENCY POLICY}

Although the literature has identified a number of potential market and behavioral failures that are relevant to energy efficiency, for policy responses to improve economic efficiency, they must successfully reduce these failures and the associated benefits must exceed the cost of implementing the policy. In Section 4, we identified a number of relevant market failures, several of which are not unique to energy efficiency and conservation. For example, R\&D spillovers exist throughout the economy, and motivate general policies such as patent protection, R\&D tax credits, and basic research funding. Policy decisions specific to energy efficiency R\&D arise mainly in the context of determining the level and allocation of public-research spending among different purposes (for a related discussion, see Newell 2008). LBD spillovers are similar in that any emerging technology may exhibit nonappropriable gains from learning, raising questions over the appropriate bounds on policy.

The environmental externalities avoided by energy efficiency and conservation largely result from emissions associated with burning fossil fuels. Economic theory suggests that if 
consumers are optimizing and there are no other market imperfections, a first-best policy to address the environmental externalities would ensure that the external cost from emissions is added to the energy price, such as through a Pigouvian tax or cap-and-trade system. The resulting internalization of the externality would lead to reduced energy demand (more conservation) and more energy efficiency investment.

To assess the amount of energy savings from such an emissions price policy, one can examine the price elasticity of energy demand discussed earlier, which is typically done in the context of a computable general equilibrium model or other aggregate energy-economic model. In the context of climate policy, such modeling typically finds that a significant portion of costeffective emissions reductions are achieved through energy efficiency and conservation, alongside renewable energy, nuclear power, and carbon capture and storage applied to coal (Clarke et al. 2006, Weyant et al. 2006). Policies to promote energy efficiency directly are second-best responses to environmental externalities, however, because they do not discriminate among the emissions intensities of different energy sources, do not provide an incentive for reducing consumption of energy services, and tend to apply only to a subset of sources. Instead, policies to promote energy efficiency may be the appropriate response to demonstrated behavioral failures, particularly in contexts where that behavior has broader societal implications (e.g., environmental externalities).

The remaining discussion focuses on the economic rationale, effectiveness, and cost of policies that are specifically targeted to energy efficiency grouped into three broad categories: information programs, incentives, and product standards. Before turning our attention to these issues, we briefly review some generic issues that arise in measuring the effectiveness and cost 
of energy efficiency policies. For a more detailed review of these issues, see Gillingham et al. (2006).

\subsection{Issues in Measuring Energy Efficiency Policy Effectiveness and Cost}

The literature on energy efficiency and conservation policy evaluation is extensive and has become more sophisticated with time. There are a few critical issues common to energy efficiency policies. First, ex ante studies dominate much of the energy efficiency policy literature, particularly for evaluating product standards. These studies form a valuable starting point for understanding future policy, but they do not demonstrate that policies have been effective or net beneficial in actual implementation. As more energy efficiency and conservation policies have been implemented, the literature is shifting to ex post studies that examine the historical effectiveness and cost of energy efficiency and conservation policies in order to improve future policy making.

One of the major criticisms of the energy efficiency and conservation policy evaluation literature is that "free riders" are not always properly accounted for. Free riders are consumers who would have invested in energy efficiency or conserved energy absent the policy, but who receive additional benefits from the policy (Joskow \& Marron 1992). Benefits from free riders should not be counted in the benefits from the policy, but costs (that are not simply transfers) should be included in the costs of the policy. As discussed above, papers in the broader energy efficiency literature point to an offsetting effect of “free drivers," where nonparticipants in the program are induced to invest in energy efficiency or conserve energy as a result of having

observed program participants (Blumstein \& Harris 1993, Eto et al. 1996, Geller \& Attali 2005).

Another common criticism of energy efficiency policy evaluations is that they either ignore or inappropriately account for the rebound effect, such that energy efficiency 
improvements decrease the marginal cost of energy services, thereby increasing demand and inducing less-than-proportional reductions in energy use. There is an extensive debate in the literature about the importance of the rebound effect in the context of energy efficiency standards (for a review, see Gillingham et al. 2006), but some empirical evidence suggests it may be numerically small in the case of energy efficiency standards (Dumagan \& Mount 1993). For example, Davis (2008) examined the case of clothes washers and found a relatively small, but not insignificant, rebound effect of $-6 \%$. For recent evidence in the household transportation context, see Small \& Van Dender (2007).

\subsection{Information Programs}

Information programs typically aim to induce energy efficiency investments by providing information about potential energy savings or examples of energy savings. Some programs attempt to promote energy conservation, particularly for electricity during times when the electricity grid is stressed. Historically, many information programs have been part of utility demand-side management (DSM) programs, and others have been federal programs such as Energy Star, appliance labels, and home energy ratings for new homes. Information programs also include programs that provide feedback to consumers about their energy consumption.

Information programs are motivated by the informational problems and behavioral failures noted above. The intention is that, by providing greater and more reliable information, issues of uncertain future returns and asymmetric information may be lessened. Additional information may also lower the cognitive cost of energy decision making or help guide consumers toward better decisions.

Information programs vary greatly, both in their method and implementation, and evidence of their effectiveness is mixed. Weil \& McMahon (2003) offered anecdotal evidence 
that product labeling requirements can be successful in increasing energy-efficient investments, but Levine et al. (1995) found that the Energy Guide product labeling requirements were fairly ineffective. The Energy Guide label has been revised in a recent rule made to improve its effectiveness. According to some studies, voluntary Energy Star labels appear to have achieved significant savings by inducing greater energy efficiency (Webber et al. 2000). For example, Howarth et al. (2000) presented evidence that the voluntary Environmental Protection Agency Green Lights program (now part of Energy Star) and Energy Star office products program have been effective in increasing energy efficiency investments by increasing access to information.

Anderson \& Newell (2004) examined industrial energy audits and found that, although plants accept only approximately half of the recommended projects, most plants respond to the costs and benefits presented in the energy audits and, with the additional information, adopt investments that meet hurdle rates consistent with the standard investment criteria the audited firms say they use. Newell et al. (1999) found that the responsiveness of energy-efficient product innovation to energy prices increased substantially after product labeling was required. Stern (1985) suggested that many early energy conservation information programs (particularly DSM programs) were not very effective. Fischer (2008) examined the psychological literature on feedback programs (i.e., programs that provide consumers real-time information about their electricity consumption) and found feedback induces energy conservation with typical savings of 5\%-12\%. Reiss \& White (2008) examined data from the 2000-2001 California electricity crisis and found that, in times of crisis, conservation appeals and information programs can produce sustained reductions in energy demand. Data indicating the cost effectiveness of these programs are not readily available. 


\subsection{Financial Incentives}

Incentive programs provide financial motivation for energy efficiency investments through direct subsidies, tax credits, tax deductions, rebates, or loan subsides. Financial incentives have also been used to promote energy conservation in the electricity market during times of peak load. In addition, financial incentives have been used to encourage the development of new energy technologies, such as through prizes for highly energy-efficient products (Gillingham et al. 2006). Incentive programs have been primarily implemented as part of utility DSM programs. These programs are broadly motivated by the concerns mentioned above, in effect responding to the perceived underinvestment in energy efficiency by subsidizing such investment.

The findings from empirical evidence on the effectiveness of financial incentives are mixed. Stern (1985) suggested financial incentives are not very effective in inducing initial interest in energy efficiency improvement programs, but they may help induce energy efficiency investments by those already participating in the programs. Using a survey about the conservation tax credits of the early 1980s, Carpenter \& Chester (1984) found that, although $86 \%$ of those surveyed were aware of the credit, only $35 \%$ used it, and of those who used it, $94 \%$ would have invested anyway. Several studies econometrically estimate the effect of state tax incentives on all conservation investments and find mixed results. Hassett \& Metcalf (1995) attempted to correct previous methodological errors and estimated that a change of 10 percentage points in the tax price for energy investment increases the probability of making an energy efficiency investment by 24\%. Williams \& Poyer (1996) also found that despite the free-rider issue, tax credits increased the probability of an energy efficiency investment using data on the 1980s tax credit. These results suggest that financial incentives may be effective, but further research is needed to determine their cost effectiveness. 
There is a fairly extensive literature examining the cost effectiveness of utility DSM programs, which typically contain financial incentives along with information programs. Common values in the literature of the "negawatt cost" or the full life-cycle cost (i.e., total expense of running the program and installing equipment) per kilowatt-hour saved as a result of a DSM program, range from below $\$ 0.01 / \mathrm{kWh}$ to above $\$ 0.20 / \mathrm{kWh}$ saved (in real 2002 dollars). For comparison, the U.S. average residential electricity price has been in the range of $\$ 0.08$ 0.09/kWh (in real 2002 dollars) over the past ten years (Energy Information Administration 2008). A debate in the literature continues regarding negawatt costs, with recent econometric evidence by Loughran \& Kulick (2004) suggesting utilities are overestimating energy savings, thus leading to costs on the high end. However, an analysis on the same data by Auffhammer et al. (2008) points out that the savings summary statistic used by Loughran \& Kulick (2004) was unweighted, and thus in this case, it underestimates the national average of electricity saved per dollar spent on DSM programs. Auffhammer et al. (2008) found a weighted average negawatt cost in the range of $0.05-0.13 \$ / \mathrm{kWh}$ based on the model by Loughran and Kulick and failed to reject the null hypothesis that the utility-reported savings estimates are correct on average. These figures include only costs to the utilities, however, not to the energy end user; consumer costs

may be in the range of $60-70 \%$ of utility costs (Nadel \& Geller 1996). Taking utility estimates of costs and effectiveness as given, Gillingham et al. (2004) calculated a cost effectiveness for all DSM programs of $\$ 0.034 / \mathrm{kWh}$ (in 2002 dollars) saved in 2000 using only utility costs and utility self-reported savings.

\subsection{Product Standards}

Product standards set a minimum level of energy efficiency that all covered products on the market must meet. In some cases, standards may be differentiated by size and type of the 
product, such as refrigerator standards that may be different for mini fridges than they are for full-sized refrigerators. Energy efficiency standards are politically motivated by the full range of concerns noted above. From an economic perspective, other policy responses tend to be more direct, efficient responses to the market failures described. For example, if consumers are making rational decisions and there is heterogeneity in their preferences for energy efficiency, product standards could lead to a loss in economic efficiency by forcing behavior change on those who gain relatively little from energy efficiency (e.g., those who do not use the product often) (Hausman \& Joskow 1982). On the other hand, verified behavioral failures could provide an economic rationale for product standards.

The literature on product standards focuses for the most part on appliance standards, for which there are primarily ex ante estimates of cost and effectiveness based on government regulatory analysis. Using engineering estimates of the energy savings and energy prices, Meyers et al. (2003) found a cumulative net benefit of \$17.4 billion over 1987-2000 for the 1987-2000 appliance standards. With projections of future energy savings added, they found a cumulative net benefit of the current standards of \$154 billion for 1987-2050 (both figures in 2003 dollars). Taking these estimates as given, Gillingham et al. (2004) calculated an implied cost effectiveness of $\$ 0.028 / \mathrm{kWh}$ saved in 2000 .

These net-benefit estimates have, to our knowledge, not been subject to independent verification in the economic literature. Because these analyses do not include a valuation of environmental or security externalities, their net benefits arise solely from implicit modeling assumptions that are different from the way consumers behave in the absence of product standards (i.e., implicitly modeling behavioral failures). The implication is either that consumers 
are not minimizing costs, or that the model is making incorrect assumptions. Further empirical research evaluating the degree to which each of these cases is more correct would be valuable.

\section{CONCLUSION}

The literature on the economics of energy efficiency and conservation has embodied significant debate over the past few decades, yet many outstanding issues remain. The heart of the debate centers on the issues of identifying the economically efficient level of energy efficiency, of determining whether policy directed specifically toward energy efficiency is necessary to bring us to this level, and, if this is so, of determining its net benefits in practice. We identify potential market and behavioral failures that may help to explain this gap, although quantitative evidence on the magnitude of many of these potential failures is limited.

Many of the commonly cited market failures are not unique to energy efficiency, and addressing them calls for a much broader policy response, such as an economy-wide price on greenhouse gases to address climate change, comprehensive innovation policy to increase innovative effort, and electricity market reforms moving toward marginal cost pricing. Conversely, information and behavioral failures — to the extent that they are substantial — tend to motivate more specific energy efficiency policies, provided that the benefits of the policies exceed the costs. Further research in this vein is essential to clarify better the potential for energy efficiency policies to increase economic efficiency. 


\section{REFERENCES}

Akerlof G. 1970. The market for lemons: quality uncertainty and the market mechanism. Q. J. Econ. 84:488-500

Anderson S, Newell R. 2004. Information programs for technology adoption: the case of energyefficiency audits. Resour. Energy Econ. 26:27-50

Arrow K. 1962. The economic implications of learning by doing. Rev. Econ. Stud. 29:155-73

Auffhammer M, Blumstein C, Fowlie M. 2008. Demand-side management and energy efficiency revisited. Energy J. 29:91-104

Bass F. 1980. The relationship between diffusion rates, experience curves, and demand elasticities for consumer durable technological innovations. J. Bus. 53:51-67

Bernstein M, Griffin J. 2005. Regional Differences in the Price-Elasticity of Demand for Energy. Santa Monica, CA: RAND Corp.

Berry L. 1984. The role of financial incentives in utility-sponsored residential conservation programs: a review of customer surveys. Eval. Program Plann. 7:131-41

Blumstein C, Harris J. 1993. The cost of energy efficiency. Science 261:970

Blumstein C, Kreig B, Schipper L, York C. 1980. Overcoming social and institutional barriers to energy efficiency. Energy 5:355-72

Bohi D, Toman M. 1996. Economics of Energy Security. Norwell, MA: Kluwer Acad.

Bohi D, Zimmerman M. 1984. An update on econometric studies of energy demand behavior. Annu. Rev. Energy 9:105-54

Brennan T. 2004. Market failures in real-time metering. J. Regul. Econ. 26:119-39

Camerer C. 1997. Progress in behavioral game theory. J. Econ. Perspect. 11:167-88

Carpenter EH, Chester TS. 1984. Are federal energy tax credits effective? A Western United States survey. Energy J. 5:139-49

Clarke L, Wise M, Placet M, Izaurralde C, Lurz J, et al. 2006. Climate change mitigation: an analysis of advanced technology scenarios. Work. Pap. 16078, Pac. Northwest Natl. Lab.

Dahl C. 1993. A survey of energy demand elasticities in support of the development of the NEMS. Work. Pap., Colorado Sch. Mines, US Dep. Energy

Davis L. 2008. Durable goods and residential demand for energy and water: evidence from a field trial. Rand J. Econ. 39:530-46

DeCanio SJ. 1993. Barriers within firms to energy-efficient investments. Energy Policy 21:90614

DeCanio SJ. 1994a. Agency and control problems in U.S. corporations: the case of energyefficient investment projects. J. Econ. Bus. 1:105-24

DeCanio SJ. 1994b. Why do profitable energy-saving investment projects languish? J. Gen. Manag. 20:62-71 
DeCanio SJ, Watkins W. 1998. Investment in energy efficiency: Do the characteristics of firms matter? Rev. Econ. Stat. 80:95-107

Dumagan JC, Mount TD. 1993. Welfare effects of improving end-use efficiency: theory and application to residential electricity demand. Resour. Energy Econ. 15:175-201

Energy Information Administration. 2008. Electric Power Monthly with Data for September 2008. Washington, DC: US Dep. Energy/EIA

Eto J, Vine E, Shown L, Sonnenblick R, Payne C. 1996. The total cost and measured performance of utility sponsored energy-efficiency programs. Energy J. 17:31-52

Fischer C. 2005. On the importance of the supply side in demand-side management. Energy Econ. 27:165-80

Fischer C. 2008. Feedback on household electricity consumption: a tool for saving energy? Energy Effic. 1:79-104

Fischer C, Newell R. 2008. Environmental and technology policies for climate mitigation. $J$. Environ. Econ. Manag. 55:142-62

Friedman L. 2002. Bounded rationality versus standard utility-maximization: a test of energy price responsiveness. In Judgements, Decisions, and Public Policy, ed. R Rowda, J Fox, pp. 138-73. New York: Cambridge Univ. Press

Friedman L, Hausker K. 1988. Residential energy consumption: models of consumer behavior and their implictions for rate design. J. Consum. Policy. 11:287-313

Geller H, Attali S. 2005. The Experience with Energy Efficiency Policies and Programmes in IEA Countries: Learning from the Critics. Paris: Int. Energy Agency

Gillingham K, Newell R, Palmer K. 2004. Retrospective examination of demand-side energy efficiency policies. Discuss. Pap. 04-19, Resour. Future

Gillingham K, Newell R, Palmer K. 2006. Energy efficiency policies: a retrospective examination. Annu. Rev. Environ. Resour. 31:161-92

Gillingham K, Newell R, Pizer W. 2008. Modeling endogenous technological change for climate policy analysis. Energy Econ. 30:2734-53

Golove W, Eto J. 1996. Market barriers to energy efficiency: a critical reappraisal of the rationale for public policies to promote energy efficiency. Work. Pap. LBL-38059:UC-1322, Lawrence Berkeley Natl. Lab.

Goulder L, Schneider S. 1999. Induced technological change and the attractiveness of CO2 emissions abatement policies. Resour. Energy Econ. 21:211-53

Griliches Z. 1995. R\&D and productivity: econometric results and measurement issues. In Handbook of the Economics of Innovation and Technical Change, ed. P Stoneman, pp. 5271. Oxford: Blackwell

Hall B. 1996. The private and social returns to research and development. In Technology, $R \& D$, and the Economy, ed. LR Smith, CE Barfield, pp. 140-83. Washington, DC: Brookings Inst. Am. Enterp. Inst. 
Hartman R, Doane M, Woo C-K. 1991. Consumer rationality and the status quo. Q. J. Econ. 106:141-62

Hassett KA, Metcalf GE. 1993. Energy conservation investment: Do consumers discount the future correctly? Energy Policy 21:710-16

Hassett KA, Metcalf GE. 1995. Energy tax credits and residential conservation investment: evidence from panel data. J. Public Econ. 57:201-17

Hausman J. 1979. Individual discount rates and the purchase and utilization of energy-using durables. Bell J. Econ. 10:33-54

Hausman JA, Joskow PL. 1982. Evaluating the costs and benefits of appliance efficiency standards. Am. Econ. Rev. 72:220-25

Hirst E. 1986. Actual energy savings after retrofit: electrically heated homes in the Pacific Northwest. Energy 11:299-308

Holcomb J, Nelson P. 1992. Another experimental look at individual time preference. Ration. Soc. 4:199-220

Howarth R, Andersson B. 1993. Market barriers to energy efficiency. Energy Econ. 15:262-72

Howarth RB, Haddad BM, Paton B. 2000. The economics of energy efficiency: insights from voluntary participation programs. Energy Policy 28:477-86

Howarth RB, Sanstad AH. 1995. Discount rates and energy efficiency. Contemp. Econ. Policy 13:101-9

Hsing Y. 1994. Estimation of residential demand for electricity with the cross-sectionally correlated and time-wise autoregressive model. Resour. Energy Econ. 16:255-63

Jaffe A, Newell R, Stavins R. 2004. The economics of energy efficiency. In Encyclopedia of Energy, ed. C Cleveland, pp. 79-90. Amsterdam: Elsevier

Jaffe A, Newell R, Stavins R. 2005. A tale of two market failures: technology and environmental policy. Ecol. Econ. 54:164-74

Jaffe A, Stavins R. 1994. The energy efficiency gap: What does it mean? Energy Policy 22:80410

Jaffe A, Stavins R, Newell R. 1995. Dynamic incentives of environmental regulations: the effects of alternative policy instruments on technology diffusion. J. Environ. Econ. Manag. 29:S43-63

Joskow P, Tirole J. 2007. Reliability and competitive electricity markets. Rand J. Econ. 38:6084

Joskow PL, Marron DB. 1992. What does a negawatt really cost? Evidence from utility conservation programs. Energy J. 13:41-74

Kahneman D, Tversky A. 1979. Prospect theory: an analysis of decisions under risk. Econometrica 47:263-91

Kempton W, Feuermann D, McGarity A. 1992. I always turn it on "super”: user decisions about when and how to operate room air conditioners. Energy Build. 18:177-91 
Kempton W, Montgomery L. 1982. Folk quantification of energy. Energy 7:817-27

Koomey J, Sanstad A. 1994. Technical evidence for assessing the performance of markets affecting energy efficiency. Energy Policy 22:826-32

Levine M, Koomey J, McMahon J, Sanstad A, Hirst E. 1995. Energy efficiency policy and market failures. Annu. Rev. Energy Environ. 20:535-55

Levinson A, Niemann S. 2004. Energy use by apartment tenants when landlords pay for utilities. Resour. Energy Econ. 26:51-75

List J, Price M. 2009. What do behavioral and neural economics have to offer environmental and resource economics? Annu. Rev. Resour. Econ. 1: In press

Loewenstein G, Prelec D. 1992. Anomalies in intertemporal choice: evidence and an interpretation. Q. J. Econ. 107:573-97

Loughran D, Kulick J. 2004. Demand-side management and energy efficiency in the United States. Energy J. 25:19-41

Lutzenhiser L. 1992. A cultural model of household energy consumption. Energy 17:47-60

Lutzenhiser L. 1993. Social and behavioral aspects of energy use. Annu. Rev. Energy Environ. 18:247-89

Machina M. 1989. Dynamic consistency and non-expected utility models of choice under uncertainty. J. Econ. Lit. 32:1622-68

McFadden D. 1999. Rationality for economists? J. Risk Uncertain. 19:73-105

Metcalf G. 2008. An empirical analysis of energy intensity and its determinants at the state level. Energy J. 29:1-26

Metcalf GE. 1994. Economics and rational conservation policy. Energy Policy 22:819-25

Metcalf GE, Hassett KA. 1999. Measuring the energy savings from home improvement investments: evidence from monthly billing data. Rev. Econ. Stat. 81:516-28

Meyers S, McMahon JE, McNeil M, Liu X. 2003. Impacts of U.S. federal energy efficiency standards for residential appliances. Energy 28:755-67

Murtishaw S, Sathaye J. 2006. Quantifying the effect of the principal-agent problem on US residential use. Work. Pap. LBNL-59773, Lawrence Berkeley Natl. Lab.

Nadel S, Geller H. 1996. Utility DSM: What have we learned? Where are we going? Energy Policy 24:289-302

Nadiri IM. 1993. Innovations and technological spillovers. Work. Pap. 4423, NBER

Newell R. 2008. A U.S. innovation strategy for climate change mitigation. Discuss. Pap. 200815, Brookings Inst. Hamilton Project

Newell R, Jaffe A, Stavins R. 1999. The induced innovation hypothesis and energy-saving technological change. Q. J. Econ. 114:941-75

Newell R, Pizer W. 2008. Carbon mitigation costs for the commerical building sector: discretecontinuous choice analysis of multifuel energy demand. Resour. Energy Econ. 30:527-39 
Popp D. 2002. Induced innovation and energy prices. Am. Econ. Rev. 92:160-80

Popp D, Newell R, Jaffe A. 2009. Energy, the environment, and technological change. In Handbook of Economics of Technical Change, ed. B Hall, N Rosenberg. Oxford: NorthHolland

Rabin M. 1997. Psychology and economics. J. Econ. Lit. 36:11-46

Ray D. 1998. Development Economics. Princeton, NJ: Princeton Univ. Press

Reiss P, White M. 2008. What changes energy consumption? Prices and public pressures. Rand J. Econ. 39:636-63

Ruderman H, Levine M, McMahon J. 1987. The behavior of the market for energy efficiency in residential appliances including heating and cooling equipment. Energy J. 8:101-24

Sanstad A, Blumstein C, Stoft S. 1995. How high are option values in energy efficiency investments. Energy Policy 23:739-43

Sanstad A, Hanemann M, Auffhammer M. 2006. End-use Energy Efficiency in a "Post-Carbon" California Economy: Policy Issues and Research Frontiers. Berkeley, CA: Calif. Clim. Chang. Cent.

Sanstad AH, Howarth RB. 1994. Consumer rationality and energy efficiency. Presented at Proc. Summer Study Energy Effic. Build., Berkeley, CA

Schneider S, Goulder L. 1997. Achieving carbon dioxide emissions reductions at low cost. Nature 389:13-14

Sebold FD, Fox EW. 1985. Realized savings from residential conservation activity. Energy J. 6:73-88

Shogren J, Taylor L. 2008. On behavioral-environmental economics. Rev. Environ. Econ. Policy 2:26-44

Simon H. 1959. Theories of decision-making in economics and behavioral science. Am. Econ. Rev. 49:253-83

Simon H. 1986. Rationality in psychology and economics. J. Bus. 59:209-24

Small K, Van Dender K. 2007. Fuel efficiency and motor vehicle travel: the declining rebound effect. Energy J. 28:25-51

Stein J. 2003. Agency, information, and corporate investment. In Handbook of the Economics of Finance, ed. G Constantinides, M Harris, R Stulz. Amsterdam: Elsevier

Stern P, ed. 1985. Energy Efficiency in Buildings: Behavioral Issues. Washington, DC: Natl. Acad. Press

Sue Wing I. 2008. Explaining the declining energy intensity of the U.S. economy. Resour. Energy Econ. 30:21-49

Sutherland RJ. 1991. Market barriers to energy efficiency investments. Energy J. 12:15-34

Sutherland RJ. 1996. The economics of energy conservation policy. Energy Policy. 24:361-70

Thaler R. 1981. Some empirical evidence on dynamic inconsistency. Econ. Lett. 8:201-7 
Thaler R. 1991. Quasi-Rational Economics. New York: Russell Sage Found.

Train K. 1985. Discount rates in consumers' energy-related decisions: a review of the literature. Energy 10:243-53

Tversky A. 1972. Elimination by aspects: a theory of choice. Psychol. Rev. 79:281-99

Tversky A, Kahneman D. 1974. Judgement under uncertainty: heuristics and biases. Science 185:1124-31

van Benthem A, Gillingham K, Sweeney J. 2008. Learning-by-doing and the optimal solar policy in California. Energy J. 29:131-51

van Soest DP, Bulte E. 2000. Does the energy-efficiency paradox exist? Technological progress and uncertainty. Environ. Resour. Econ. 18:101-12

Wade S. 2003. Price Responsiveness in the AEO2003 NEMS Residential and Commercial Buildings Sector Models. Washington, DC: US Dep. Energy/EIA

Webber CA, Brown RE, Koomey JG. 2000. Savings estimates for the ENERGY STAR voluntary labeling program. Energy Policy 28:1137-49

Weil S, McMahon J. 2003. Governments should implement energy-efficiency standards and labels---cautiously. Energy Policy 31:1403-15

Weyant JP, de la Chesnaye FC, Blanford GJ. 2006. Overview of EMF-21: multigas mitigation and climate policy. Energy J. Spec. Issue Multi-Greenh. Gas Mitig. Clim. Policy: 1-32

Williams M, Poyer D. 1996. The effect of energy conservation tax credits on minority household housing improvements. Rev. Black Polit. Econ. 24:122-34

Wilson C, Dowlatabadi H. 2007. Models of decision making and residential energy use. Annu. Rev. Environ. Resour. 32:169-203

Wolak F. 2006. Residential customer response to real-time pricing: the Anaheim Critical-Peak Pricing Experiment. Work. Pap. 151, Energy Inst. Cent. Study Energy Mark., Univ. Calif. Berkeley

Yates S, Aronson E. 1983. A social psychological perspective on energy conservation in residential buildings. Am. Psychol. 38:435-44

Zobler N, Hatcher K. 2003. Financing energy efficiency projects. Gov. Financ. Rev. Feb. 14-18 